\title{
Effects of Legislative Mandates, Education Type, and Education Provider on Concussion Education for Student Athletes
}

\author{
Miriam Carroll-Alfano ${ }^{1,2, ~ *, ~ R o b e r t a ~ D e P o m p e i ~}{ }^{3}$, Nickola Wolf Nelson ${ }^{2}$ \\ ${ }^{1}$ Department of Communication Science and Disorders, Saint Xavier University, Chicago, US \\ ${ }^{2}$ Interdisciplinary Health Sciences, Western Michigan University, Kalamazoo, US \\ ${ }^{3}$ School of Speech-Language Pathology and Audiology, University of Akron, Akron, US \\ Email address: \\ alfano@sxu.edu (M. Carroll-Alfano),rdepom1@uakron.edu (R. DePompei), nickola.nelson@wmich.edu (N. W. Nelson) \\ ${ }^{*}$ Corresponding author
}

\section{To cite this article:}

Miriam A. Carroll-Alfano, Roberta DePompei, Nickola Wolf Nelson. Effects of Legislative Mandates, Education Type, and Education Provider on Concussion Education for Student Athletes. American Journal of Sports Science. Vol. 7, No. 3, 2019, pp. 94-102. doi: $10.11648 /$ j.ajss.20190703.13

Received: June 23, 2019; Accepted: July 19, 2019; Published: August 5, 2019

\begin{abstract}
Most states in the United States have enacted legislation mandating concussion education for student-athletes; however, it is not clear if such legislation leads to all students receiving the mandated education or if this education is associated with greater awareness of concussion symptoms. This work investigates whether collegiate student-athletes report receiving legislatively-mandated concussion education, and whether this varies by gender and sport. This study also investigates what methods are being used to deliver education, who is providing the education, and if receiving education is associated with an increase in ability to name the various signs and symptoms of concussion. One hundred and fifty-seven collegiate athletes from a private Midwestern university completed anonymous surveys asking about participation in high school concussion education programs, the type of education received, and who provided it. Participants were also asked to name concussion symptoms. Despite legislative mandates, $20 \%$ of student-athletes reported not receiving concussion education in high school, with women more likely to report not receiving education relative to men. The percentage reporting not receiving legislatively-mandated concussion education did not decrease over the five year period since legislation went into effect. The most common education method reported was casual conversation, and the most common providers were athletic trainers and coaches. Athletes reporting education showed no difference in ability to name concussion signs and symptoms, compared to those who reported no education. The type of education provided and the role of the person providing the education was not associated with ability to name a cognitive or behavioral signs and symptom. Legislatively-mandated concussion education is either not being delivered to all student-athletes or is not being delivered in a manner that can be remembered and reported. Education as currently being delivered is not effective in increasing awareness of diverse cognitive and behavioral signs and symptoms of concussion.
\end{abstract}

Keywords: Concussion Education, Legislation, Student-Athletes

\section{Introduction}

Concussions, also termed mild traumatic brain injuries, are the most common form of traumatic brain injuries. Sports-related concussions, especially those involving children or adolescents, are a major public health concern in the United States, and are the subject of increasing discussion among health professionals and in the popular media [1-3]. The Centers for Disease Control and Prevention (CDC) has reported that between 2010 and 2016, there was an average of nearly 285,000 emergency room visits by children under the age of 18 for concussions from sport or recreational activities [4]. The number of reported sportsrelated concussions in adolescents has increased over the last 10 years $[5,6]$.

Following a concussion, a variety of concussion-related 
signs and symptoms may occur. In the literature, these signs and symptoms are often grouped into specific domains, such as physical, somatic, sleep-related, cognitive, behavioral, emotional, and affective [1,7-10]. One common grouping is to separate symptoms into physical (including sleep and somatic), cognitive, and behavioral (including affective and emotional) categories [10]. Physical signs and symptoms include headaches, visual disturbances, and fatigue; cognitive signs and symptoms include memory loss and attention difficulties, and behavioral signs and symptoms include depression and changes in mood [1, 7-10]. Behavioral and cognitive concussion symptoms are less commonly recognized than physical symptoms [11-14]. Serious long-term health effects that have been found in athletes with a history of concussions include long-term cognitive deficits, dementia, depression, and chronic traumatic encephalopathy [15-18].

Children and adolescents are more vulnerable to the serious effects of concussions than adults [19, 20], and may have longer recovery times than adults [9]. Additionally, concussion-induced cognitive deficits are particularly serious for children and adolescents because of the potential impact on their academic performance [21]. Repeated concussions have been shown to have a cumulative effect on student athletes [19]. The vulnerability of youth to the effects of concussion give rise to the need for concussion education and awareness among student athletes. Despite increased efforts in this area, studies have demonstrated deficits in student-athletes' knowledge of concussion symptoms, especially behavioral symptoms [11-13, 22].

State governments have turned to legislation to address this problem. In the United States, all 50 states and the District of Columbia have passed concussion legislation [23]. Nearly all of these laws include mandatory concussion education programs for high school athletes; however, there is variability regarding the details of the educational mandates [23]. Relevant to this study, which drew upon a population of student athletes who came almost exclusively from the states of Illinois and Indiana, these two states enacted concussion legislation in July, 2011, which required all high school athletes to receive concussion education [24, 25]. Therefore, beginning with the graduating class of 2012 , all high school athletes in Illinois and Indiana should have received concussion education.

With the passage of concussion legislation by many states mandating concussion education to high school athletes, it is important to address if these requirements are being followed, and if student athletes are reporting receiving this mandated education while in high school. Previous studies investigating the question about prior education have reported that a sizeable portion of student-athletes indicate that they did not received education, even when it is mandated by legislation [11, 26]. After implementation of legislatively mandated education, a significant increase was observed in the portion of student-athletes reporting receiving education; however, two years after implementation, nearly $25 \%$ of student-athletes continued to report not receiving this mandated education [11]. It remains an open question whether implementation has stalled at this level of compliance; or if the percent of student athletes reporting not receiving mandated education will slowly increase over time as implementation of the legislation gradually improves.

The likelihood of a student-athlete reporting not receiving mandated education has been found to be impacted by the sport played, with volleyball and basketball players being more likely to report not receiving education, and football players having the highest rates of reporting education [11]. The recognition of the vulnerability of adolescent athletes to the effects of concussion was largely driven by instances of concussion in football that were widely publicized in the public media [1], thus it is not surprising that initially, the likelihood of receiving education varied with the sport played. After enactment of legislation and the passage of time, however, these differences should slowly be eliminated and concussion education should be evenly distributed among the various sports being played, as well as between genders.

Legislation may lead to a greater prevalence of high school athletes reporting receiving education, however; research investigating whether concussion education is associated with better knowledge of the symptoms of concussion has shown mixed results. Some investigations have shown concussion education to be associated with a statistically significant improvement of athletes' knowledge of symptoms [27, 28], whereas other studies have shown little or no association between education and concussion knowledge [12, 29, 30].

An important consideration in evaluating the effectiveness of concussion education in leading to greater knowledge of concussion symptoms is to look at the methods used to deliver this education. Education can be delivered in a variety of formats, such as formalized in-person training, videos, handouts, and casual conversations. Research has suggested that various methods of delivery may have different levels of efficacy in achieving post-education gains in concussion knowledge [30-32]. Quizzes and videos have been found to be less effective than other delivery methods in being able to achieve increases in concussion knowledge [31]. Lecture-based pedagogical techniques have been found to lead to modest increases in concussion knowledge immediately following the training session, but changes in reporting intent found not to be impacted [30, 32]. In one study, athletes expressed a preference for video-based training [32]. Some general principles and theoretical frameworks have been applied for concussion education programs, with knowledge transfer, learning styles, and identifying who is receiving the training as important items to consider for the development of training programs [3336].

Additionally, education can be provided by a variety of persons, including athletic trainers, coaches, school nurses, athletic directors, or doctors. The effectiveness of education in achieving post-education gains in concussion knowledge 
may be dependent upon the role of the person providing the training, particularly whether or not the person is a medical professional. For example, schools that have an athletic trainer on staff have been found to have student athletes with greater knowledge of concussion than schools without an athletic trainer [37], and student-athletes have expressed a preference to receive concussion education from a medical professional, rather than a coach or athletic director [14].

This study was designed to address the following research questions.

1. Has the percent of athletes reporting receiving education after enactment of legislatively mandated concussion education continued to increase with time post-legislation?

2. Is there an association between collegiate athletes reporting having received concussion education in high school with sport played and gender?

3. What methods do student-athletes report as being used to deliver concussion education, and who do they report is providing the education?

4. Is there an association between reporting having received specific methods of concussion education from specific providers and being able to name the diverse symptoms of concussions?

\section{Methodology}

\subsection{Research Design and Procedures}

The research design was a cross sectional associational survey study. Collegiate student-athletes participated in an anonymous survey that asked questions about their knowledge of concussion symptoms, and about their participation in, and the nature of, any previous concussion education. The data-collection survey was administered prior to concussion education seminars that all freshman and transfer athlete attended as part of their college-level participation in a school-sponsored intercollegiate athletics program. Participants were informed of the nature of the research study both verbally and in writing, and instructed that their participation was not mandatory and they would not be penalized if they chose not to participate, under a protocol approved by two universities' Human Subjects Institutional Review Boards. Consent by participants was provided verbally. The surveys were administered during six separate concussion education sessions conducted between March 2015 and March 2017.

\subsection{Participants}

Participants were 157 collegiate student-athletes from a single National Association of Intercollegiate Athletics (NAIA) university. Approximately $90 \%$ of the athletes in this study attended high school in Illinois, with 5\% attending high schools in Indiana, and 5\% in other states. Almost all (98.7\%) participants had graduated from high school during a period when mandated high school concussion education was in effect in their state because of legislation.

\subsection{Data-Collection Instrument}

The data-collection instrument consisted of a survey developed for this study based on prior literature. Demographic information was collected, which included academic year (freshman, sophomore, junior, senior), gender (male/female), sport or sports played, high school graduation year, and high school graduation state. Participants were asked whether they had received previous concussion education. If the athlete reported participating in education, additional questions were asked about the education, including when they had participated (middle school/junior high, high school, college, or other), what types of education were provided (formal group training, casual conversation, watched a video/slides, handouts, signed a form), and who provided the training (coach, athletic trainer, athletic director, doctor, nurse, other). Concussion symptoms knowledge was probed by asking the participant an openended question to enumerate symptoms of a concussion. Participants were also asked if they had had a previous concussion history and if so, whether they had sought treatment. Signs and symptoms of concussions that were named by students in response to the open-ended question were classified into one of three categories, physical, cognitive, and behavioral, based on the literature [10].

\subsection{Data Analysis}

Statistical investigations were conducted using IBM SPSS Statistics Version 24. A Pearson Chi-Squared test was used to test the statistical significance $(\alpha=0.05)$ of the association of reporting receiving concussion education with gender, with the various sport/gender combinations, with high school graduation year, and with the ability to name a cognitive sign or symptom. For statistically significant results, the odds ratios were calculated.

For method of receiving education and person providing education, participants could select more than one option and thus each option was modeled as separate binary variable. Binary logistic regression was used for analysis of the association of ability to name a cognitive sign/symptom with education method and with the role of person providing education. An alpha level of $<0.05$ was used for all analyses.

The data collection instrument in this study had several questions that were identical with those used in a previous research study on the same population, including questions that had asked if the participant had received concussion education [11]. This commonality between the two data collection instruments and their target population (studentathletes at the same university) made it possible to combine the new data from this study with the data from the prior study for these identical questions. This single combined dataset was used to investigate how the reported rates of concussion education varied over a time period of nine graduation years based on data from 406 participants. These combined data were analyzed with descriptive statistics and with a Pearson Chi-Square test to test the association between reports of receiving concussion education and 
graduating pre- and post-legislation.

\section{Results}

\subsection{Demographic Information}

Demographic information is summarized in Table 1. Survey results were obtained from 157 participants, who comprised of $63.1 \%$ men and $36.9 \%$ women, representing eight different sports. Participants attended high school in Illinois $(89.8 \%)$, Indiana (4.5\%), and Michigan (1.9\%), as well as six other states, each with less than $1 \%$. Seventy six percent of participants were freshman, and the remaining $24 \%$ were students who transferred to the university as sophomores, juniors, or seniors. Of the 157 participants, 44 (28.0\%) reported experiencing a concussion, and of these, 40 $(90.9 \%)$ reported seeking medical treatment for the concussion.

Table 1. Demographic Information of Participants.

\begin{tabular}{llll}
\hline Sport & & Percent & n \\
\hline \multirow{6}{*}{} & Football & 34.4 & 54 \\
& Soccer & 15.9 & 25 \\
& Baseball & 10.8 & 17 \\
& Volleyball & 9.6 & 15 \\
& Softball & 9.6 & 15 \\
& Basketball & 8.3 & 13 \\
& Cross country/track & 8.3 & 13 \\
& Cheerleading & 1.9 & 3 \\
& Golf & 1.3 & 2 \\
Sender & & & \\
& Men & 63.1 & 99 \\
& Women & 36.9 & 58 \\
& IL & & \\
& IN & 89.8 & 141 \\
& MI & 4.7 & 7 \\
& Other states/countries & 1.9 & 3 \\
\hline
\end{tabular}

\subsection{Proportion of Athletes Reporting Education}

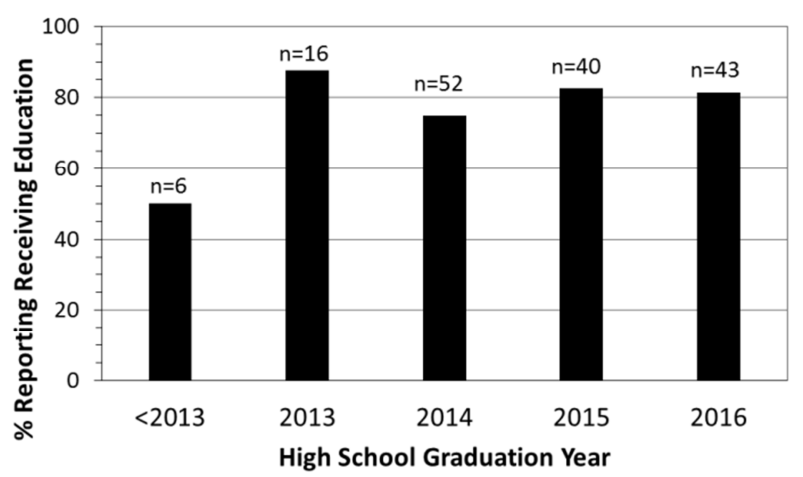

Figure 1. Percentage of athletes reporting receiving concussion education by high school graduation year $(N=157)$.

Of the 157 participants, 124 (79.0\%) reported having received concussion education, with the remaining 33 $(21.0 \%)$ reporting not receiving any education. A graph of high school graduation year vs. percent reporting education is shown in Figure 1. For graduation years 2013, 2014, 2015, and 2016, the percent reporting receiving education fell in a range between $75 \%$ and $87 \%$, as can be seen in Figure 1. No statistically significant difference was observed across these graduation years $\left(\chi^{2}(3)=1.590, p=0.66\right.$, Pearson chi-square).

Of the 124 participants who reported having received education, $8(6.5 \%)$ reported receiving the education in middle school, 108 (87.1\%) in high school, 41 (33.1\%) in college, and $6(4.8 \%)$ in some other setting (park district, club sport, fire department). The totals add to more than $100 \%$ as participants may have reported receiving education at multiple times.

As described previously, the new data from this study were combined with data from a previous study [11] at the same Midwestern university on the same population, in which several identical survey questions were asked. Thus, it was possible to examine the rate of reported concussion education over nine graduation years using results from 406 total participants. Results based on this combined dataset are represented in Figure 2, which presents the percentage of student-athletes reporting receiving concussion education for high school graduation years between 2008 and 2016. In this combined dataset, approximately $95 \%$ of the participants attended high school in either Illinois or Indiana. Participants were separated into two groups: athletes who graduated before legislation went into effect in Illinois or Indiana (graduation year $<2012$ ) and athletes who graduated after legislation went into effect (graduation year $>=2012$ ). As can be seen in Figure 2, a lower percentage of athletes reported receiving education pre-legislation $(59.5 \%)$ versus post-legislation $(78.2 \%)$. This difference was statistically significant $\left(\chi^{2}(1)=16.43, p<.001, \mathrm{OR}=2.44\right.$, Pearson chisquare). Post-legislation, reported rates of receiving concussion education ranged between $75 \%$ and $82 \%$.

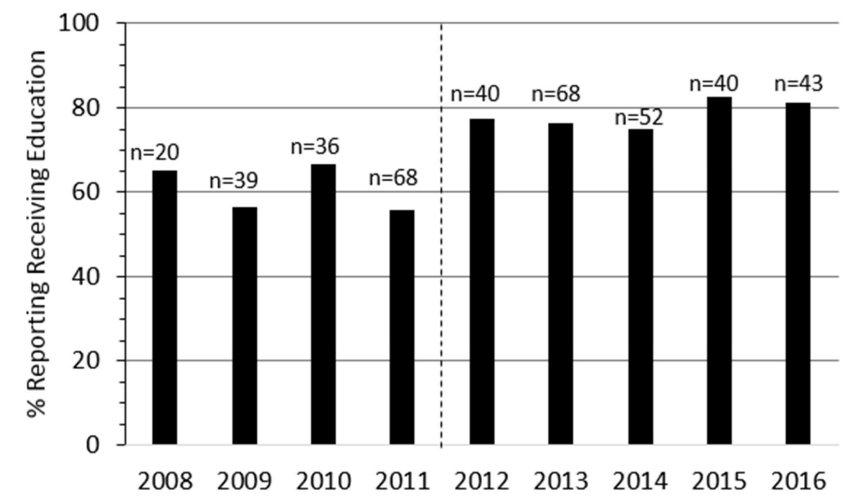

Figure 2. Combined dataset showing the percentage of athletes reporting receiving concussion education by high school graduation year $(N=406)$. The vertical dashed line shows when concussion legislation went into effect in Illinois and Indiana.

\subsection{Proportion of Athletes Reporting Education by Gender and Sport}

When analyzing education by gender, men reported receiving education at a rate of $84.8 \%$ and women at a rate of $69.0 \%$. This difference was statistically significant 
$\left(\chi^{2}(1)=5.56, p=0.02\right.$, odds ratio $=2.52$, Pearson chi-square $)$.

Figure 3 shows the percentage of participants who reported receiving education by sport and gender. Six different categories of sports are shown in Figure 3 football, baseball/softball, basketball, cross-country/track, soccer, and volleyball. For each category of sport, the percent reporting receiving education is shown for men, for women, and for men and women combined. Overall, volleyball players had the highest percentage reporting receiving education, and cross country/track athletes had the lowest. To determine if these differences were statistically significant, a chi square test was performed to examine the association between reported education and the sport/gender combination (e.g. women's basketball, men's basketball). No statistically significant difference was found among the various gender-sport combinations $\left(\chi^{2}(13)=18.68, p=0.13\right.$, Pearson chi-square).

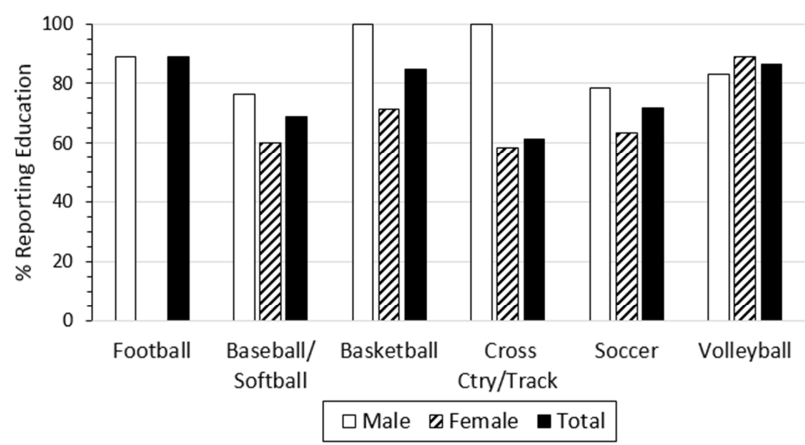

Figure 3. Percentage of athletes who reported receiving concussion education, by sport and gender.

Football players were found to be statistically more likely to report receiving education than athletes playing a different sport than football $\left(88.9 \%\right.$ vs. $73.8 \%, \chi^{2}(1)=4.87, p=0.03$, odds ratio $=2.84$, Pearson chi-square). As all football players were men, this difference may reflect the previously reported gender difference in education rates. To test this, a Pearson chi-square test was run to examine the percent of athletes reporting receiving education comparing football players to men in all other sports. The percentage of football players reporting education was $88.9 \%$ and the percentage of male non-football players reporting education was $80.0 \%$. This difference was not statistically significant $\left(\chi^{2}(1)=1.51\right.$, $\mathrm{p}=0.22$, Pearson chi-square).

\subsection{Methods Used for Education and Who Provided Education}

Athletes were asked to characterize all methods of the concussion education that they had previously received. Casual conversation was the most common method of concussion education reported, and was selected by $54.8 \%$ of participants, followed by watching a video or slide show (31.8\%) of participants, formal group training (30.6\%), receiving handouts $(22.3 \%)$, signing a form $(19.1 \%)$, and other types of training $(4.5 \%)$. Note that these percentages total more than $100 \%$ because participants could select more than one education method.

Nearly a quarter (23.3\%) of athletes did not report receiving any methods of training, 28.0\% reported receiving a single method, and $26.1 \%$ reported two methods. Smaller percentages reported 3 methods $(17.2 \%)$ and four or more methods (7.6\%). Athletes who reported receiving concussion education were asked to identify the role of the person who provided the education. The most common persons providing education were athletic trainers $(65.6 \%)$ and coaches $(42.0 \%)$, followed by athletic directors $(15.3 \%)$, doctors $(9.6 \%)$, nurses $(7.0 \%)$, and other providers $(2.5 \%)$. Totals add to more than $100 \%$ because training could be provided by more than one person and may have occurred more than once.

Participants who reported experiencing a concussion were more likely to report receiving education from a doctor (11 out of $44,25.0 \%$ ), compared to those who reported not having a previous concussion (4 out of 107, 3.7\%). This difference was statistically significant $(\mathrm{p}<0.001$, odds ratio $=6.69$, Fisher's exact test).

\subsection{Association Between Type of Education and Naming Symptoms}

Athletes were tested on their concussion knowledge by asking them to name concussion signs symptoms. Nearly all participants $(97.4 \%)$ correctly named at least one valid sign or symptom. Participants named a total of 462 signs and symptoms (an average of 2.94 symptoms named per participant), of which $447 \quad(96.8 \%)$ were generally recognized as being indicative of concussion, and 15 of which were not symptoms of concussion. A symptom was considered as valid if it was contained in the generally recognized list of symptoms of concussion $[1,5,10]$. The incorrect signs and symptoms named by participants were generally symptoms of a more serious traumatic brain injury, such as dilated pupils, and were excluded from further analysis.

Participants provided a total of 462 responses when asked to enumerate concussion signs and symptoms. Of these, 15 $(3.2 \%)$ were considered invalid, with most of these being symptoms of more serious TBIs (e.g. dilated pupils). The remaining 447 valid responses enumerated a total of 15 distinct signs or symptoms. The top three symptoms named were headache (named 106 times), dizziness (90 times), and nausea/vomiting (66 times). These top three signs and symptoms were all physical symptoms, and accounted for nearly $60 \%$ of the total symptoms named. Rounding out the top 10 were memory impairment (46 times), fatigue/lethargic (22 times), blurred/double vision (22 times), hypersensitivity to light (22 times), disorientation (17 times), light headedness (15 times), and impaired coordination (14 times). The top ten symptoms accounted for about $94 \%$ of the total. Memory impairment was the most reported cognitive sign or symptoms, at for $10.3 \%$ of the total signs and symptoms named. Emotional lability was the only reported behavioral sign or symptom named, comprising less than $1 \%$ of the 
total.

Figure 4 shows the percentage of athletes naming at least one sign or symptom for each of the three sign and symptom categories (physical, cognitive, behavioral), stratified by whether the athlete reported receiving education. Athletes in both groups named at least one physical sign or symptom of a concussion at a high rate $(98.4 \%$ with training, $84.8 \%$ without training). For cognitive signs and symptoms, 30.3\% of athletes with education correctly named at least one cognitive sign or symptom, compared to $41.9 \%$ of athletes without education. For behavioral signs and symptoms, none of the participants without training named a behavioral sign or symptom, and only $1.3 \%$ of those with training named at least one correct behavioral sign or symptom, as seen in Figure 4. This difference in the percent of participants who named a cognitive sign or symptom with and without education was not statistically significant $\left(\chi^{2}(1)=1.48\right.$, $p=0.22$, Pearson chi-square). Differences in percent of participants who named physical or behavioral signs or symptoms was not statistically analyzed due to the low variance in the responses (i.e. almost everyone named a physical sign or symptom and almost no one named a behavioral sign or symptom).

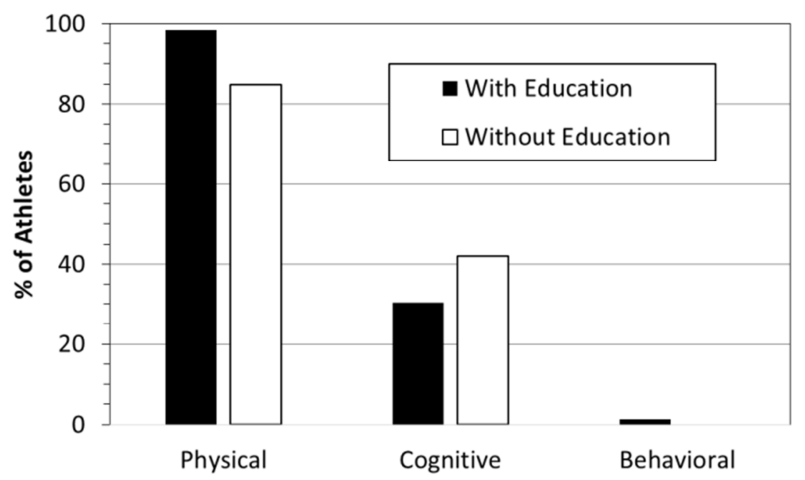

Figure 4. Percentage of athletes naming at least one concussion sign or symptom in the specified category.

Table 2. Logistic Regression Results for Named Cognitive Symptom vs. Educational Method.

\begin{tabular}{lll}
\hline Method & Odds Ratio & $\mathbf{9 5 \%}$ Confidence Interval \\
\hline Formal Group Training & 0.74 & {$[0.36,1.55]$} \\
Casual Conversation & 0.50 & {$[0.25,1.03]$} \\
Video or Slide Training & 1.08 & {$[0.52,2.26]$} \\
Handouts, no Presentation & 4.03 & {$[1.45,11.19]$} \\
Signed a Form & 0.69 & {$[0.26,1.84]$} \\
Other Training & 0.35 & {$[0.07,1.76]$} \\
\hline
\end{tabular}

Model $X^{2}(6)=11.90, p=0.064 . R^{2}=0.073$ (Cox \& Snell), 0.099 (Nagelkerke).

Logistic regression was used to determine the association between the method of concussion education reported and being able to name a cognitive sign or symptom of concussion, and the results are summarized in Table 2. For this analysis, only cognitive symptoms were considered, because physical and behavioral symptoms both had small expected sizes for some cells. There was no association between the method of training reported and whether an athlete named a cognitive sign or symptom $\left(\chi^{2}(6)=11.90, p=\right.$ $0.06)$.

Logistic regression showed no association between reporting having received education from a specific type of provider and being able to name a cognitive sign and symptom of concussion $\left(\chi^{2}(6)=4.08 p=0.67\right)$. A summary of the logistic regression results is seen in Table 3.

Table 3. Logistic Regression Results for Named Cognitive Symptom vs. Education Provider.

\begin{tabular}{lll}
\hline Provider & Odds Ratio & 95\% Confidence Interval \\
\hline Coach & 0.94 & {$[0.46,1.93]$} \\
Athletic Trainer & 1.42 & {$[0.69,2.92]$} \\
Athletic Director & 2.00 & {$[0.80,5.01]$} \\
Doctor & 1.13 & {$[0.33,3.85]$} \\
Nurse & 0.49 & {$[0.28,4.49]$} \\
Other & 0.47 & {$[0.05,5.02]$} \\
\hline
\end{tabular}

Model $\mathrm{X}^{2}(6)=4.08, \mathrm{p}=0.666 . \mathrm{R}^{2}=0.026$ (Cox \& Snell), 0.035 (Nagelkerke).

\section{Discussion}

This study found that a large portion (21\%) of student athletes continue to report not receiving legislativelymandated concussion education while in high school, despite attending high school in a state where legislation has mandated education for all student athletes. This lack of reported education persisted up to five years after the passage of legislation mandating this education. Additionally, of the $79 \%$ who reported receiving education, only $87 \%$ of these reported receiving this education in high school, suggesting that the actual percentage receiving education in high school may be even lower.

All students in the combined dataset (Figure 2) who graduated in 2012 or later should have reported receiving legislatively-mandated concussion education. While a significant increase in reported education was observed after implementation of legislatively-mandated concussion education, the percent reporting education has since plateaued at around $80 \%$, with no improvements observed beyond the initial increase seen between 2011 and 2012. About $20 \%$ of athletes continue to report not receiving education up to five years after it became mandatory. These athletes either did not receive education, or they received education but did not recall participating. The lack of a steady increase of students reporting education over time suggests that implementation of the legislation has stalled, and the desired effect of the legislation is not impacting one student out of five.

This apparent failure of legislation to achieve full implementation may result from a number of factors. The legislation in Illinois and Indiana does not provide funding or other financial resources needed to implement what are potentially costly educational mandates $[24,25]$. Also, the legislation is written with very general guidelines that lack specific details or reference implementations that would make it easier for schools to achieve compliance. Finally, this legislation does not provide enforcement mechanisms that impose financial or other penalties on those schools that 
do not achieve compliance. The reasons for the apparent failure of legislation to produce full compliance among the affected schools is an important public policy question that merits further study.

When the data from the current study were analyzed by gender, a statistically significant difference was seen between men and women, with men reporting education at a higher rate. One possible explanation for men reporting receiving this education at higher levels than women may be that this education has been especially targeted at football players and virtually all football players are men. In the popular media, one of the driving forces on the need for concussion legislation has been widely-publicized incidents of chronic traumatic encephalopathy (CTE) in former professional football players [1]. Thus, there has been an emphasis on the need for football players at all levels of play to receive concussion education. This study showed that there was a statistically significant difference between the rate of reporting receiving education between football players and non-football-playing athletes of both genders; however, when football players were compared to male nonfootball-playing athletes, no statistically significant difference was observed. These results suggest that the difference in reported rates between men and women athletes cannot be explained by higher education rates for football players, as football players do not exhibit significantly higher training rates than non-football-playing men. This difference in the percentage of male athletes versus female athletes' reporting education was not seen in the previous research [11] and is an area that merits further study.

Of the top three reported providers of education (athletic trainers, coaches, and athletic directors), only one is a health care professional (athletic trainers). Coaches and athletic directors are much less likely than athletic trainers to have advanced medical training, and this may impact the quality of concussion education that they are able to deliver. Previous work has found that athletes at a high school with an athletic trainer on staff report greater knowledge of concussion than schools without an athletic trainer [37]. Additionally, research has shown that athletes preferred receiving concussion education from a medical professional, such as a doctor or athletic trainer, rather than from someone who is not a medical professional, such as a coach or athletic director [14].

Less than $10 \%$ of participants reported receiving education from a doctor; however, participants who reported experiencing a concussion were nearly seven times more likely to report education from a doctor than those who did not experience a concussion $(25.4 \%$ vs $3.7 \%)$. The likely reason for this large difference is that nearly all $(>90 \%)$ of the participants who experienced a concussion sought medical treatment. During this treatment, they were likely to have personal interactions with a doctor, which provided the opportunity for the doctor to provide education. This type of education is an example of "just in time training", where the information and education being provided directly applies to the recipient, making the recipient much more likely to pay attention and be engaged in the process.

The results of this study showed no statistically significant association between an athlete naming a cognitive sign and symptom and the method of training reported. One might expect that formal classroom training on concussions might be more effective in enabling athletes to name cognitive signs and symptoms than other methods, such as a casual conversation, watching a video, or simply signing a form, but this was not seen in this study. Also, the lack of knowledge of cognitive and behavioral symptoms relative to physical symptoms found in this study has been reported in prior studies [11, 13, 14]. These results highlight the need for evidenced-based education programs that have been proven effective in increasing awareness of the diverse symptoms of concussion. Other investigators have proposed some general principles for implementation of concussion education programs [33-36], and these principles may serve as a foundation to build education programs that will lead to improved abilities to enumerate the full diversity of concussion symptoms.

\section{Limitations and Future Directions}

This study was a retrospective study which relied on participants' ability to recall receiving concussion education that they may have had in the past, and specific details about that education. An athlete's ability or lack of ability to recall participating in concussion education may reflect the quality or type of education that was provided. Future research could employ alternate techniques for determining if high school student athletes are receiving concussion education, such as surveying high school athletic departments to determine what concussion education programs they provide to their athletes.

Some sample sizes were small when stratified by sport and gender, leading to low statistical power and possible type II errors for some of the statistical analysis. Finally, all participants in this study attended a private NAIA university in the Midwest. Future research needs to continue to look at these questions in a variety of universities, including public vs. private, Division I vs. Division III, and various geographic regions, to probe the generalizability and external validity of these findings.

This study made no attempt to ascertain the reasons why student athletes reported not receiving mandated education, and why women were more likely to report not receiving education relative to men. The reasons for this apparent failure of legislation to achieve full compliance, years after it went into effect, is an important public policy question that merits further study.

\section{Conclusions}

Over five years after the passage of legislation mandating concussion education for student athletes in two Midwestern states, one in five athletes reported not receiving this education in high school. Either this education is not being 
delivered to all student-athletes or is not being delivered in a manner that can be remembered and reported. Women are less likely to report receiving this mandated education than men. Determining the reasons for lack of full compliance, particularly among women, is a public policy question meriting additional investigation.

Much of the current education provided to student athletes is being delivery by people who are not health care professionals, such as coaches and athletic directors. Education as currently being delivered is not effective in increasing awareness of diverse cognitive and behavioral symptoms of concussion.

\section{Recommendations}

This study supports several recommendations. First, continued efforts should be considered to ensure that student athletes are receiving mandated concussion education, starting in middle school and high school, or even earlier, and that the education being provided is sufficiently meaningful as to be remembered by the athletes. Second, even with education, there are deficiencies in student athletes' knowledge, particularly in identification of cognitive and behavioral signs and symptoms, which may lead them to ignore these symptoms if they experience them after a concussion, either immediately or sometime later. Concussion education programs should address these gaps. Finally, additional research is needed to determine which methods and providers are most beneficial for delivering effective and meaningful concussion education to student athletes.

\section{Conflicts of Interest}

The authors have no financial, consultant, institutional or other relationships that might lead to bias or conflict of interest.

\section{References}

[1] Cantu, R, Hyman, M. Concussions and our kids. New York, NY. Houghton Mifflin Harcourt (2012).

[2] Centers for Diseases Control and Prevention. Report to Congress on Traumatic Brain Injury in the United States: Epidemiology and Rehabilitation. National Center for Injury Prevention and Control; Division of Unintentional Injury Prevention, Atlanta, GA. http://www.cdc.gov/traumaticbraininjury/pubs/congress_epi_r ehab.html. 2015. Accessed October 16, 2016.

[3] Giza CC, Kutcher JS, Ashwal S, et al. Summary of evidencebased guideline update: Evaluation and management of concussion in sports. Neurology. 2013; 80 (24): 2250-2257.

[4] Sarmiento K, Thomas KE, Daugherty J, et al. Emergency Department Visits for Sports- and Recreation-Related Traumatic Brain Injuries Among Children - United States, 2010-2016. MMWR Morb Mortal Wkly Rep 2019; 68: 237 242. DOI: http://dx.doi.org/10.15585/mmwr.mm6810a2.
[5] Coronado VG, Haileyesus T, Cheng TA, et al. Trends in Sports- and Recreation-Related Traumatic Brain Injuries Treated in US Emergency Departments: The National Electronic Injury Surveillance System-All Injury Program (NEISS-AIP) 2001-2012. Journal of Head Trauma Rehabilitation. 2015; 30 (3): 185-197.

[6] Zhang AL, Sing DC, Rugg CM, et al. The Rise of Concussions in the Adolescent Population. Orthopaedic Journal of Sports Medicine. 2016; 4 (8): 1-7.

[7] American Academy of Neurology. Concussion during Sports Activities: Summary of Evidence-based Guideline for Patients https://www.aan.com/Guidelines/Home/GetGuidelineContent/ 586 2019; Accessed April, 2019.

[8] Centers for Disease Control and Prevention. Concussion Signs and Symptoms, Retrieved from https://www.cdc.gov/headsup/basics/concussion_symptoms.ht ml. 2019; Accessed April, 2019.

[9] McCrory, P, Meeuwisse, W, Dvorak, J, Aubry, M, Bailes, J. Brogilio, S., et al. Consensus statement on concussion in sport - the 5th international conference on concussion in sport. British Journal of Sports Medicine, 2017; 51 (11): 838-84.

[10] Stoler DR, Hill BA. Coping with Concussion and Mild Traumatic Brain Injury, New York, NY: Avery (2013).

[11] Carroll-Alfano MA. Mandated high school concussion education and collegiate athletes' understanding of concussion. Journal of Athletic Training. 2017; 52 (7): 689-697.

[12] Cournoyer J and Tripp BL. Concussion knowledge in high school football players. Journal of Athletic Training. 2014; 49 (5): 654-658.

[13] Fedor A, Gunstad J. Limited knowledge of concussion symptoms in college athletes. Applied Neuropsychology: Adult. 2015; 22 (2): 108-113.

[14] Knollman-Porter, K, Brown, J., Flynn, M. Preliminary Examination of Concussion Knowledge by Collegiate Athletes and Non-Athletes. American Journal of SpeechLanguage Pathology 2018; 27: 778-795

[15] Bramlett, H. M., Dietrich, W. D. Long-Term Consequences of Traumatic Brain Injury: Current Status of Potential Mechanisms of Injury and Neurological Outcomes. Journal of Neurotrauma, 2015; 32 (23): 1834-1848.

[16] Corrigan J. D., and Hammond F. M. Traumatic brain injury as a chronic health condition. Arch. Phys. Med. Rehabil. 2013; 94: 1199-1201.

[17] Institute of Medicine and National Research Council. Sportsrelated concussions in youth: Improving the science, changing the culture. National Academies Press. October 30, 2013.

[18] Masel B. E., and DeWitt D. S. Traumatic brain injury: a disease process, not an event. Journal of Neurotrauma, 2010; 27: $1529-1540$.

[19] Guskiewicz KM, McCrea M, Marshall SW, et al. Cumulative effects associated with recurrent concussion in collegiate football players: The NCAA concussion study. Journal of the American Medical Association. 2003; 290 (19): 2549-2555.

[20] Scorza K, Raleigh M, O'Connor F. Current concepts in concussion: evaluation and management, American Family Physician. 2012; 85 (2): 123-132. 
[21] Halstead ME, Mcavoy K, Devore CD., et al. Returning to learning following a concussion. Pediatrics. 2013; 132 (5): 948-957.

[22] Chrisman SP, Quitiquit C, Rivara FP. Qualitative study of barriers to concussive symptom reporting in high school athletics. Journal of Adolescent Health. 2013; 52 (3): 330335 .

[23] The Network for Public Health Law. Summary matrix of state laws addressing concussions in youth sports. March 31, 2016 https://www.networkforphl.org/_asset/7xwh09/StateLawsTabl eConcussions_2-19-13.pdf. Accessed January 2019.

[24] State of Illinois. Illinois public act 097-0204, "Protecting our student athletes act”. July, 2011. http://www.ilga.gov/legislation/publicacts/97/PDF/0970204.pdf. Accessed January 2019.

[25] State of Indiana. Indiana public act IC 20-34-7. May 2011 http://www.in.gov/legislative/bills/2011/ES/ES0093.2.html. Accessed January, 2019.

[26] Chrisman SP, Schiff MA, Chung SK, et al. Implementation of concussion legislation and extent of concussion education for athletes, parents, and coaches in Washington state. American Journal of Sports Medicine. 2014; 42 (5): 1190-1196.

[27] Bagley AF, Daneshvar DH, Schanker BD, et al. Effectiveness of the SLICE program for youth concussion education. Clinical Journal of Sport Medicine 2012; 22 (5): 385-389.

[28] Parker E, Gilchrist J, Shuster D, et al. Reach and Knowledge Change among coaches and other participants of the online course: "Concussion in sports: what you need to know", Journal Head Trauma Rehabilitation, 2015; 30 (3): 198-206.

[29] Kurowski B, Pomerantz WJ, Schaiper C, et al. Factors that influence concussion knowledge and self-reported attitudes in high school athletes. Journal of Trauma and Acute Care Surgery. 2014; 77 (3 SUPPL. 1): S12-S17.
[30] Kurowski, B. G., Pomerantz, W. J., Schaiper, C. Gittelman, M. Impact of preseason concussion education on knowledge, attitudes, and behaviors of high school athletes. Journal of Trauma and Acute Care Surgery. 2015; 79 (3): S21-S28.

[31] Cusimano, M, Zhang S, Topolovec-Vranic, J, Grosso, A, Jing R., Ilie, G. Pros and Cons of 19 Sport-Related Concussion Educational Resources in Canada: Avenues for Better Care and Prevention. Frontiers in Neurology. 2018; 9: Article 872.

[32] Kroshus, E, Daneshvar, D., Baugh, C, Nowinski, N, Cantu, R. NCAA concussion education in ice hockey: an ineffective mandate. British Journal of Sports Medicine. 2014; 48: 135140 .

[33] Provvidenza C, Engebretsen L, Tator C, et al. From consensus to action: Knowledge transfer, education and influencing policy on sports concussion. British Journal of Sports Medicine. 2013; 47 (5): 332-338.

[34] Sady MD, Vaughan CG, Gioia GA. School and the concussed youth: Recommendations for concussion education and management. Physical Medicine and Rehabilitation Clinics of North America. 2011; 22 (4): 701-719.

[35] Sullivan, L, Pursell, L, Molcho, M. Evaluation of a theorybased concussion education program for secondary school student-athletes in Ireland. Health Education Research, 2018; 33 (6): 492-504.

[36] Vassilyadi M, Duquette C, Shamji MF, et al. Evaluation of Thinkfirst for kids injury prevention curriculum for grades 7/8. Canadian Journal of Neurological Sciences. 2009; 36 (6): 761-768.

[37] Wallace, J., Covassin, T., Nogle, S., Gould, D., Kovan, J. Concussion Knowledge and Reporting Behavior Differences Between High School Athletes at Urban and Suburban High Schools. Journal of School Health. 2017; 87 (9): 665-674. 